\title{
The Nature and Consequences of Thermal Interactions Twixt
}

\section{Core and Mantle}

\author{
David E. LOPER \\ Geophysical Fluid Dynamics Institute, Florida State University, Tallahassee, FL 32306, U.S.A.
}

(Received January 5, 1990; Revised July 8, 1990)

\begin{abstract}
It is now well accepted that only a part of the heat flux from the Earth's interior is due to radioactive decay; a significant portion of the flux is due to secular cooling of the Earth (StACEY, 1980; JACKSON and PollaCK, 1984; Christensen, 1985; STACey and LOPER, 1988), and it follows directly that the core and mantle are cooling, albeit at differing rates (STACEY and LOPER, 1984). The cooling of the core, and the concomitant freezing of the inner core, is believed to be responsible for the operation of a gravitationally powered geomagnetic dynamo. The flux of heat from the core is convected upward through the mantle via plumes, whose surface expression is hotspots such as that at Hawaii. In this brief review, current ideas on the structure and dynamics of the core and mantle will be discussed and related to surface features and processes that result from the thermal interaction between core and mantle.
\end{abstract}

\section{Early Thermal Evolution}

It is generally agreed that the Earth was hot immediately following accretion and differentiation of core and mantle. A plausible scenario is that differentiation was contemporaneous with accretion and the graviational energy released during these processes combined in some unknown proportion to heat both core and mantle to a molten state (MELOSH and TONKS, 1989). The effects of bombardment and separation also would have churned the mantle into a homogeneous and adiabatic state.

Subsequently, the mantle would have cooled very quickly to its liquidus by convective motions driven by cooling from above. Since the liquidus gradient $(\mathrm{d} T / \mathrm{d} p)_{L}$ is steeper than the adiabat $(\mathrm{d} T / \mathrm{d} p)_{A}$ in the mantle (e.g., see STACEY, 1977), the liquidus is first reached at the base of the mantle. Further cooling would produce a region of mixed phase below the liquid, either a slurry of solid crystals suspended in the liquid or a mush of solid crystals interpenetrated by liquid. This region, too, would cool quickly by counter-flow convection (upward percolation of liquid and downward movement of solid; e.g., see WARREN, 1985), until the solidus temperature is reached. Since $(\mathrm{d} T / \mathrm{d} p)_{s}>(\mathrm{d} T / \mathrm{d} p)_{A}$, the solidus would have been reached first at the base of the mantle. The continued rapid cooling within the one- and two-phase regions above the solidus interface would have caused it to rise quickly to the surface of the Earth. We shall take the instant the mantle became completely solid as "time zero", i.e., the end of the period of early evolution. Subsequent cooling of the mantle proceeded much more slowly (i.e., on a geologic time scale) by subsolidus convection. This cooling has been modeled in a number of studies; for reviews see SCHUBERT, 1979; SleEP and LANGAN, 1981; Christensen, 1985. 
As the early mantle cooled rapidly, first by liquid convection then by counter-flow convection, the core cooled in step. However, when the base of the mantle reached the solidus, counter-flow convection ceased to be in contact with the top of the core and the heat flux from the core decreased drastically. The core heat flux subsequently increased over geologic time as a thermal boundary layer developed at the base of the mantle.

The inner core is believed to be composed of the solid phase which forms from solidification of the liquid outer core, and is continuing to grow as the Earth cools (JACOBS, 1953; LOWES, 1984). It is possible that the central portion of the inner core might have formed during the accretion process due to pressure freezing or early rapid cooling. Pressure freezing might have occurred as the central pressure increased during continued accretion following initial formation of the core. Since the liquidus temperature increases with pressure, it is possible that some initially molten core material became frozen due to the increase of core pressure. Additionally, it is possible that some of the inner core solidified during the initial phase of rapid cooling before the base of the mantle solidified.

If a portion of the solid inner core is the result of pressure freezing or rapid cooling, the amount of gravitational energy available to drive the dynamo over geologic time would be correspondingly reduced. Using Eq. (25) of FEARN and LOPER (1985), we see that the power available to drive the dynamo decreases rapidly with the fraction, $f$, of the inner core formed prior to time zero, with the power becoming zero when $f=1 / 3$. The fact that the Earth has a robust magnetic field suggests that little, if any, of the inner core was formed prior to time zero. We shall assume that the core was completely molten at time zero and formation of the inner core was the result of the subsequent cooling.

Immediately following time zero, the temperature in the mantle, $T_{\mathrm{m}}$, was identical to the solidus temperature, $T_{S}: T_{\mathrm{m}}(r)=T_{S}(p)$. However, the temperature was quickly changed to adiabatic by subsolidus convection driven by cooling at the surface of the Earth. These early mantle temperature profiles did not have a large radial gradient at the base. Consequently, very little heat flux flowed across the $\mathrm{CMB}$ and the core was not cooled. In fact, if there are appreciable radioactive heat sources within the core, such as ${ }^{40} \mathrm{~K}$ (HALL and MURTHY, 1971), the core may initially have heated up. HALL and MURTHY estimate that the present rate of heat production in the core due to ${ }^{40} \mathrm{~K}$ is $10^{20}$ $\mathrm{cal} / \mathrm{yr}=1.4 \times 10^{13} \mathrm{~W} .{ }^{40} \mathrm{~K}$ has a half-life of $1.25 \times 10^{9} \mathrm{yr}$, so that the rate would have been $1.7 \times 10^{14} \mathrm{~W}$ at $4.5 \times 10^{9} \mathrm{yr}$ ago. The core has a heat capacity of roughly $2 \times 10^{27} \mathrm{~J} / \mathrm{K}$ (STACEY and LOPER, 1984). If the core were essentially insulated soon after time zero, it would have been heating due to this radioactive decay at a rate of $2.5 \times 10^{-6} \mathrm{~K} / \mathrm{yr}$. This is an enormous rate, which would result in a temperature increase of $1000 \mathrm{~K}$ in $400 \mathrm{myr}$, if the core remained insulated.

It seem unlikely that the core contains significant amount of ${ }^{40} \mathrm{~K}$, since its presence would dictate a thermal history which is incompatible with the existence of the geomagnetic field. If the core had had a solid inner portion at time zero, presumably that solid would have been deficient in ${ }^{40} \mathrm{~K}$, which would have partitioned into the liquid outer core along with the sulfur. Thus, an early period of core heating would have superheated the liquid portion of the core, and possibly melted some or all of the solid inner core. Consequently there would be no gravitational power available to drive the geomagnetic dynamo either during that interval of heating or during a subsequent interval when the temperature was gradually decreased to its initial value. Any geomagnetic field generated during that period of heating and cooling would have been sustained by thermal 
convection. STACEY and LOPER (1984) were unable to construct a model with ${ }^{40} \mathrm{~K}$ in the core which yielded a reasonable core thermal and magnetic history; they concluded that the core does not contain a significant amount of ${ }^{40} \mathrm{~K}$.

\section{Sources of Heat in the Core}

We shall consider contributions to the total heat flux from the core, $\dot{Q}$, due to radioactivity $(R)$, latent heat $(L)$, gravitational separation $(G)$ and secular cooling $(S)$ :

$$
\dot{Q}=\dot{Q}_{R}+\dot{Q}_{L}+\dot{Q}_{G}+\dot{Q_{s}}
$$

and ignore any possible contribution from electrochemical interactions or other more obscure sources. The most interesting of these is $\dot{Q}_{G}$ which results from the rearrangement of matter as the inner core grows from solidification of the outer core (BRAGINSKY, 1963; LOPER, 1978a). This heat flux begins as gravitational potential energy, but is converted to kinetic energy by convective instability during the solidification process, thence by dynamo action into magnetic energy, and finally into heat by ohmic dissipation. We shall assume that all the ohmic dissipation occurs within the core, although it is possible that a portion is dissipated directly in the lower mantle if it has significant electrical conductivity (BRAGINSKY and MEYTLIS, 1987).

Radioactive heating in the core is attributed principally to the decay of ${ }^{40} \mathrm{~K}$ which has a half life, $\tau$, of $1.25 \times 10^{9} \mathrm{yr}$ :

$$
\dot{Q}_{R}=\dot{Q}_{R 0} 2^{-t / \tau}
$$

The magnitude of $\dot{Q}_{R}$ is very uncertain with estimates ranging from 0 (SHARPE and PELTIER, 1978) to $10^{13} \mathrm{~W}$ (HALL and MURTHY, 1971). This magnitude has decreased by a factor of 12 in the past $4.5 \times 10^{9} \mathrm{yr}$, making it difficult to construct a thermal history of the core having a growing inner core and uniform source of power for the geodynamo with a significant amount of radioactive heating in the core (STACEY and LOPER, 1984).

The contribution due to crystallization of the inner core, $\dot{Q}_{L}$, is simply related to the mass rate of freezing of the inner core, $\dot{M}_{\mathrm{i}}$, by

$$
\dot{Q}_{L}=L \dot{M}_{\mathrm{i}}
$$

where $L$ is the latent heat of crystallization, which has been estimated to be from 5 to $10 \times 10^{5} \mathrm{~J} / \mathrm{kg}$ (STACEY, 1977; GUBBINS et al., 1979; VERHOOGEN, 1980).

Similarly the contribution due to gravitational separation, $\dot{Q}_{G}$, may be expressed as

$$
\dot{Q}_{G}=G \dot{M}_{\mathrm{i}}
$$

where (LOPER, 1984)

$$
G=g_{\mathrm{c}} r_{\mathrm{c}}\left(\frac{\Delta \rho}{\rho}\right)_{\mathrm{i}}\left(\frac{3}{10}-\frac{1}{2}\left(\frac{r_{\mathrm{i}}}{r_{\mathrm{c}}}\right)^{2}\right)
$$


with $r_{\mathrm{c}}$ and $r_{\mathrm{i}}$ being the radii of the core and inner core respectively, $g_{\mathrm{c}}$ the strength of gravity at the top of the core, $\rho_{\mathrm{i}}$ the density at the bottom of the outer core and $\Delta \rho_{\mathrm{i}}$ the density jump due to compositional change at the inner core boundary. Using $r_{\mathrm{c}}=3.6 \times 10^{6}$ $\mathrm{m}, r_{\mathrm{i}}=1.2 \times 10^{6} \mathrm{~m}, g_{\mathrm{c}}=10.7 \mathrm{~m} / \mathrm{s}^{2}, \rho_{\mathrm{i}}=1.2 \times 10^{4} \mathrm{~kg} / \mathrm{m}^{3}$ and $\Delta \rho_{\mathrm{i}}=500$ to $700 \mathrm{~kg} / \mathrm{m}^{3}$, the value of $G$ is 3.6 to $5.0 \times 10^{5} \mathrm{~J} / \mathrm{kg}$, making $\dot{Q}_{G}$ comparable to, but smaller than, the contribution due to latent heat.

The major contribution to the heat flux from the core is that due to secular cooling of the core. This may be expressed as (STACEY and LOPER, 1984):

$$
\dot{Q}_{s}=-\phi\left(\dot{T}-\frac{\gamma T}{K} \dot{p}\right)
$$

where $T$ and $p$ are representative temperature and pressure within the core, $\phi$ is the core heat capacity, $K$ is the adiabatic incompressibility,

$$
\gamma=\frac{\alpha K}{\rho C_{p}}
$$

is the Grüneisen parameter, $\alpha$ is the thermal expansion coefficient and $C_{p}$ is the specific heat. The first term on the right-hand side of the equation for $\dot{Q}_{s}$ is the familiar contribution due to cooling alone. However, as the Earth cools and contracts, the local strength of gravity increases. This in turn causes the pressure within the core to increase, compressing and heating it. This heat of adiabatic compression is represented by the second term on the right-hand side of that equation.

In order to relate the temperature within the core to the mass rate of freezing of the inner core, we must decide whether the temperature of the outer core reaches the liquidus (a) at the inner core boundary or (b) above the inner core boundary. In case a, the outer core is completely liquid and all solidification occurs directly on (or below if the inner core is a mush, see FEARN et al., 1981) the inner core boundary, while in case b, a slurry of suspended crystals exists in the region below the intersection of the liquidus and the adiabat and above the inner core boundary. In case $b$ the solid inner core grows by a combination of direct freezing and sedimentation; this is equivalent to Regime $\mathrm{B}$ of LOPER (1978b).

The possibility of the occurrence of case b in the core (e.g., see STEVENSON, 1989) is in fact an old idea (MALKUS, 1973) which was first introduced in response to the suggestion (HIGGINS and KeNNEDY, 1971; KENNEDY and HIGGINS, 1973) that the liquidus gradient in the core is less steep than the adiabat. Although the core paradox is now believed not to exist (e.g., see STEVENSON, 1980), a two-phase region within the core remains a strong possibility (LOPER and ROBERTS, 1981). The question is whether the two-phase region is in the form of a slurry within the outer core above a solid inner core (case b) or a mushy inner core below a completely molten outer core (case a). This possibility of case b led LOPER and ROBERTS (1978) to develop their thermodynamic theory of a slurry. However subsequent study revealed a number of objections case $b$ which led to the preference for case a. First, as has been reiterated recently by STEVENSON (1989), sedimentation of the denser solid particles will lead to an unacceptably large growth rate of the inner core unless the parameters of the core are carefully chosen 
to minimize sedimentation. A more serious objection is that case $b$ requires nucleation of crystals within the liquid outer core. Homogeneous nucleation can be ruled out since it occurs at appreciable rates only for large undercoolings, i.e., for large values of $\Delta T=T_{L}-T$. Heterogeneous nucleation requires suitable nuclei in the form of other solid particles, the presence of which in sufficient quantity can only be speculated. A more natural mode, that does not require nucleation, is growth of solid from the inner-core boundary into the undercooled region. From laboratory experience (e.g., see COPLEY et $a l ., 1970)$ it is seen that growth from a solid boundary occurs as narrow needle-like dendrites. This is in fact the description of case a, which should be the preferred case in the absence of any supporting evidence for case $b$.

Assuming that the temperature gradient in the outer core is adiabatic and that it intersects the liquidus at the inner core boundary, we have that

$$
\dot{T}=\left(\frac{\mathrm{d} T_{A}}{\mathrm{~d} p}-\frac{\mathrm{d} T_{L}}{\mathrm{~d} p}\right)_{\mathrm{i}} \frac{g_{\mathrm{i}}}{A_{\mathrm{i}}} \dot{M}_{\mathrm{i}},
$$

with the adiabatic gradient given by

$$
\frac{\mathrm{d} T_{A}}{\mathrm{~d} p}=\frac{\gamma T}{K}
$$

and the liquidus gradient by

$$
\frac{\mathrm{d} T_{L}}{\mathrm{~d} p}=\left(\frac{\partial T_{L}}{\partial p}\right)_{\xi}+\left(\frac{\partial T_{L}}{\partial \xi}\right)_{p} \frac{\mathrm{d} \xi}{\mathrm{d} p},
$$

where $\xi$ represents the mass-fraction of light constituents within the outer core. The first term on the right-hand side of this equation is the familiar Clausius-Clapeyron term, while the second represents the depression of the liquidus as the value of $\xi$ increases.

To quantify the terms in Eq. (10), we start with the differential form of the equation of state:

$$
\delta \mathrm{d} p=\bar{\mu} \xi \mathrm{d} \xi+(L / T) \mathrm{d} T_{L}
$$

where $\delta$ is the change of specific volume upon change of phase (at constant composition $\xi$ ) and $\bar{\mu}$ is the change of chemical potential, $\mu$, with composition: $\partial \mu / \partial \xi$ (e.g., seeLOPER and RoBERTS, 1980). From ideal-solution theory (GUGGENHEIM, 1967),

$$
\bar{\mu} \cong R T / \bar{M} \xi
$$

where $R$ is the gas constant and $\bar{M}$ is the mean molecular weight of the liquid. Assuming the inner core to be pure iron, the change of composition of the outer core is related to the growth of the inner core by $\left(r_{\mathrm{c}}^{3}-r_{\mathrm{i}}^{3}\right) \mathrm{d} \xi-3 \xi r_{\mathrm{i}}^{2} \mathrm{~d} r_{\mathrm{i}}=0$. With a hydrostatic balance in the outer core, the change of pressure at the inner core boundary is related to the growth of the inner core by $\mathrm{d} p=-(\rho g)_{\mathrm{i}} \mathrm{d} r_{\mathrm{i}}$. Combining these, we have 


$$
\frac{\mathrm{d} \xi}{\mathrm{d} p}=-\frac{1}{(\rho g)_{\mathrm{i}}} \frac{3 r_{\mathrm{i}}^{2} \xi}{\left(r_{\mathrm{c}}^{3}-r_{\mathrm{i}}^{3}\right)} \cong-\frac{1}{(\rho g)_{\mathrm{i}}} \frac{3 r_{\mathrm{i}}^{2} \xi}{r_{\mathrm{c}}^{3}}
$$

Now the liquidus gradient (10) may be expressed as

$$
\left(\frac{\mathrm{d} T}{\mathrm{~d} p}\right)_{L}=\frac{T \delta}{L}\left[1+f_{\mathrm{d}}\right]
$$

where

$$
f_{\mathrm{d}}=\frac{R T}{\bar{M} \delta} \frac{1}{(\rho g)_{\mathrm{i}}} \frac{3 r_{\mathrm{i}}^{2} \xi}{r_{\mathrm{c}}^{3}}
$$

represents the contribution of the liquidus-depression term. Lindemann's Law (STACEY and IRVINE, 1977) states that

$$
\delta=\frac{2 L}{K}\left(\gamma-\frac{1}{3}\right)
$$

The reasonably well-determined parameters in these equations are $r_{\mathrm{c}}=3.5 \times 10^{6} \mathrm{~m}$, $r_{\mathrm{i}}=1.2 \times 10^{6} \mathrm{~m}, g_{\mathrm{i}}=4.4 \mathrm{~m} / \mathrm{s}^{2}, \rho_{\mathrm{i}}=1.2 \times 10^{4} \mathrm{~kg} / \mathrm{m}^{3}, K_{\mathrm{i}}=1.3 \times 10^{12} \mathrm{~Pa}, \bar{M}=50 \mathrm{~kg} / \mathrm{kmol}$, and $R=8314 \mathrm{~J} / \mathrm{kmol} \mathrm{K}$. Less well-determined are $T=4500 \mathrm{~K}, \xi=0.09, L=8 \times 10^{5} \mathrm{~J} / \mathrm{kg}$, $\gamma=1.3-1.5$. With these values, $f_{\mathrm{d}}=0.1 \pm 0.01$. Eliminating $\delta$ from (14) using (16), we have

$$
\left(\frac{\mathrm{d} T}{\mathrm{~d} p}\right)_{L}=\left(1+f_{\mathrm{d}}\right) \frac{2 T}{K}\left(\gamma-\frac{1}{3}\right)
$$

To quantify the change of pressure with size of the inner core, we begin by parameterizing the data from Table 1 of LOPER (1978a) with

$$
p_{0}=p_{\mathrm{a}}+p_{\mathrm{k}}\left[\frac{r_{\mathrm{i}}}{r_{\mathrm{k}}}-1+\exp \left(-\frac{r_{\mathrm{i}}}{r_{\mathrm{k}}}\right)\right]
$$

where $p_{0}$ is the pressure at the center of the Earth, $p_{\mathrm{a}}=3.57 \times 10^{11} \mathrm{~Pa}, p_{\mathrm{k}}=0.27 \times 10^{11} \mathrm{~Pa}$ and $r_{\mathrm{k}}=0.8 \times 10^{6} \mathrm{~m}$. This parameterization reproduces the pressure data with an error of less than $0.5 \%$. Noting that $\mathrm{d} M_{\mathrm{i}}=A_{\mathrm{i}} \rho_{\mathrm{i}} \mathrm{d} r_{\mathrm{i}}$, we have

$$
\dot{p}_{0}=\frac{p_{\mathrm{k}}\left[1-\exp \left(-r_{\mathrm{i}} / r_{\mathrm{k}}\right)\right]}{r_{\mathrm{k}} A_{\mathrm{i}} \rho_{\mathrm{i}}} \dot{M}_{\mathrm{i}}
$$

The secular pressure increase is largest at the center of the Earth, where the pressure itself is largest. Use of (19) in (6) would lead to an overestimation of the effect of adiabatic compression. Assuming the pressure increase to be proportional to the value of pressure throughout the core, it is shown in the Appendix that the mass-averaged pressure increase is a fraction $f_{\mathrm{p}}=0.628$ of that at the center. 
Now we may write

$$
\dot{Q_{S}}=S \dot{M}_{\mathrm{i}}
$$

with

$$
S=\frac{\phi T_{\mathrm{i}} g_{\mathrm{i}}}{(A K)_{\mathrm{i}}}\left[\left(\gamma-\frac{2}{3}\right)+2 f_{\mathrm{d}}\left(\gamma-\frac{1}{3}\right)+f_{\mathrm{p}} \frac{\gamma p_{\mathrm{k}}}{r_{\mathrm{k}} \rho_{\mathrm{i}} g_{\mathrm{i}}}\left(1-\exp \left(-\frac{r_{\mathrm{i}}}{r_{\mathrm{k}}}\right)\right)\right]
$$

The first term in the square bracket of (21) represents the familiar secular cooling, as tied to the freezing rate of the inner core. The term containing $f_{\mathrm{d}}$ represents the additional effect due to depression of the liquidus by change of composition, while that containing $f_{\mathrm{p}}$ represents the heating due to adiabatic compression. With the parameter values given previously these three contributions are in the ratio 1.0:0.291:0.597. Estimating $\phi=2.0 \times 10^{27} \mathrm{~J} / \mathrm{K}$ (STACEY and LOPER, 1984), $S=24 \times 10^{5} \mathrm{~J} / \mathrm{kg}$.

Altogether

$$
\dot{Q}=\dot{Q}_{R}+[L+G+S] \dot{M}_{\mathrm{i}}
$$

with the contributions from latent heat, gravity and secular cooling roughly in the ratio $8: 4: 24$. The growth rate of the inner core can be crudely estimated by assuming a constant mass-rate of freezing for the last $4 \times 10^{9} \mathrm{yr}$, say, giving $\dot{M}_{\mathrm{i}}=8 \times 10^{5} \mathrm{~kg} / \mathrm{s}$. Alternatively the current growth rate of the core may be estimated from Fig. 2 of STACEY and LOPER (1984) to be $4 \times 10^{-12} \mathrm{~m} / \mathrm{s}$, giving a remarkably similar estimate of $8.9 \times 10^{5} \mathrm{~kg} / \mathrm{s}$. Taking $\dot{M}_{\mathrm{i}}=8.5 \times 10^{5} \mathrm{~kg} / \mathrm{s}$ and the previous estimates for $L, G$, and $S$, the current core heat flux from non-radioactive sources is estimated to be $3 \times 10^{12} \mathrm{~W}$. It should be noted that, using a somewhat different line of argument, VERHOOGEN (1980) obtained very similar estimates for $L, G$ and $S$.

The gravitational power is, according to these estimates, $3.4 \times 10^{11} \mathrm{~W}$, sufficient to sustain a geomagnetic field with a strong toroidal component. The principal loss mechanism, which might channel this power away from the dynamo, is the possibility that the heat conducted down the adiabat is greater than that transferred to the mantle, necessitating downward convection of thermally buoyant fluid. STACEY and LOPER (1984) considered this possibility because their estimated core heat flux, $1.7 \times 10^{12} \mathrm{~W}$, was lower than the conducted flux of $2.7 \times 10^{12} \mathrm{~W}$. With the higher value of core heat flux here, that drain on the dynamo power supply is significantly reduced, or possibly reversed to contribute to the dynamo process through thermal convection.

\section{Transport of Core Heat through the Mantle}

It is believed that the mantle and core convect as separate units and exchange heat by conduction across the core-mantle boundary (CMB). Continuity of heat flux across the CMB requires that $k_{\mathrm{m}} \mathrm{d} T_{\mathrm{mb}} / \mathrm{d} r=k_{\mathrm{c}} \mathrm{d} T_{\mathrm{ct}} / \mathrm{d} r$ where $r$ is the radius, $T_{\mathrm{mb}}$ is the temperature at the base of the mantle, $T_{\mathrm{ct}}$ is the temperature at the top of the core, $k_{\mathrm{m}}$ is the thermal conductivity of the mantle and $k_{\mathrm{c}}$ is that of the core. The core, being principally metallic, has a much higher thermal conductivity than the silicate mantle. Consequently the 
thermal gradient at the base of the mantle is much larger than that at the top of the core. Since to a good approximation the heat conducted down the adiabat in the core is equal to the heat transferred to the mantle, there is no thermal boundary layer at the top of the core.

On the other hand, the heat from the core cannot be conducted down the adiabat in the mantle. The amount, $\dot{Q}_{C}$, conducted down the adiabat in the mantle is given by

$$
\dot{Q}_{C}=-k A\left(\frac{\mathrm{d} T}{\mathrm{~d} r}\right)_{A}
$$

where

$$
\left(\frac{\mathrm{d} T}{\mathrm{~d} r}\right)_{A}=-\frac{\gamma T}{K} \rho g
$$

With $g=10.7 \mathrm{~m} / \mathrm{s}^{2}, \rho=5.5 \times 10^{3} \mathrm{~kg} / \mathrm{m}^{3}, A=1.5 \times 10^{14} \mathrm{~m}^{2}, T=3000 \mathrm{~K}, K=6.6 \times 10^{11} \mathrm{~Pa}$, $\gamma=0.9$ and $k=4 \mathrm{~W} / \mathrm{mK}, \dot{Q_{C}}=1.5 \times 10^{11} \mathrm{~W}$, too small by a factor of at least 20 . Consequently, heat from the core is convected upward through the mantle and a thermal boundary layer must exist at the base of the mantle. It is very tempting to associate the seismically observed $D^{\prime \prime}$ layer with the thermal boundary layer. However, quantification of that association is complicated by (at least) three factors (DoORNBOS et al., 1986): (1) Parametric sensitivity. Small changes in seismic parameters may produce large changes in estimated temperatures and temperature gradients. (2) Lack of homogeneity. The CMB region may contain zones of material (i.e., anti-continents), with densities intermediate between those of the core and mantle, and having unknown seismic properties. (3) Lack of isotropy. Shear flow at the base of the mantle may produce zones of aligned crystals. In spite of the difficulty in using seismic observations to determine the properties of the thermal boundary layer, there is little doubt of its existence since the dynamo within the core cannot operate without heat being transferred to the mantle.

The mode of convection within the mantle which carries the heat from the core to the surface of the Earth is determined by two properties of the mantle. First, the Prandtl number, $v / \kappa$, where $v$ is the kinematic viscosity and $\kappa$ is the thermal diffusivity, is very large. This implies that the thermal structures within the mantle are thin. Examples of narrow cold structures are the lithosphere and lithospheric slabs; examples of narrow hot structures are the thermal boundary layer at the base of the mantle and mantle plumes. Second, deformation and flow occur via thermally activated sub-solidus creep, with

$$
v=v_{0} \exp \left(\beta T_{S}(p) / T\right)
$$

where $\beta$ is a dimensionless constant estimated to be $30-35$. Consequently, viscosity is low and flow speeds tend to be high where the temperature is high: in the bottom boundary layer and in plumes.

YUEN and PELTIER (1980) showed that a static thermal boundary layer at the base of the mantle is dynamically unstable. The experiments of WHITEHEAD and LUTHER (1975) reveal that the initial structure of the resulting convective flow is a spherical dome of hot buoyant fluid rising into the overlying mantle. If the sphere is isolated, it will cool, slow 
and diffuse into the mantle (GRIFFITHS, 1986). However, a sphere trailing a conduit, through which buoyant material rises, can grow and rise at an accelerated pace (OLSON and SINGER, 1985). The conduit apparently can remain long after the passage of the sphere; a mathematical solution for a steady plume was obtained by LOPER and STACEY (1983). For a detailed description of mantle plumes, see LOPER (1990).

The mass flux, $\dot{M}$, required to convect upward through the mantle the heat, $\dot{Q}$, from the core is given by

$$
\dot{M}=\dot{Q} / C_{p}(\Delta T)
$$

where $\Delta T$ is the temperature excess. The value of this temperature excess is uncertain, with the most popular estimate being $800 \mathrm{~K}$. With $\dot{Q} \geq 3 \times 10^{12} \mathrm{~W}, \Delta T \leq 800 \mathrm{~K}$ and $C_{p}=1250 \mathrm{~J} / \mathrm{kg}$, we have $\dot{M} \geq 3 \times 10^{6} \mathrm{~kg} / \mathrm{s}=30 \mathrm{~km}^{3} / \mathrm{yr}$. This is a large flux when compared to rates of surface volcanism; it is more than 300 "Hawaiis" (although it is significantly less than Morgan's estimate of $500 \mathrm{~km}^{3} / \mathrm{yr}$; see MORGAN, 1972).

Where does all this hot material go? Since we know that very little of it reaches the surface, there are two possibilities; it may rise from the base of the mantle as isolated thermals which diffuse into the mantle, or it may rise through plume conduits. In the latter case, the material is unlikely to diffuse within the mantle. Rather it rises until it encounters an obstacle: the lithosphere. As the plume material approaches the lithosphere, it diverges horizontally, creating and/or enhancing the asthenosphere. Some of the material reaches the surface as hot-spot volcanism, but most remains trapped, forming the hot-spot swell (OLSON and NAM, 1986). From the surface features of hotspot swells, DAVIES (1988) has estimated the plume heat flux to be $2.5 \times 10^{12} \mathrm{~W}$, remarkably close to the present estimate of $3 \times 10^{12} \mathrm{~W}$ for the core heat flux. This coincidence of values lends support to the contention that virtually all of the core heat flux is convected to the surface of the Earth via plumes, rather than contributing to general mantle convection.

\section{Surface Effects of Core Heat}

Recently RICHARDS et al. (1989) argued that the surface expression of the spherical cap of a new plume is likely to be a continental flood basalt or oceanic plateau, with the trailing conduit forming a volcanic chain extending from the flood basalt to a presently active center of volcanic activity. They have supported this argument with simple calculations relating the volumes of several flood basalts (Deccan, Brito-Arctic, Parana and Karoo) to the volumetric output of the associated current volcanic sites (Reunion, Iceland, Tristan da Cunha and Crozet/Marion). This association can be extended to a number of other features as is shown in Table 1.

Table 1 is a compilation of data from several sources, most notably a world map of seismicity, including the panorama of ocean-floor bathymetry, produced by B. Heezen and $\mathrm{M}$. Tharpe in 1977. It is surprising how many linear volcanic features on the surface of the Earth begin at a flood basalt or oceanic plateau and end at a volcanic site with a distinctive ocean-island geochemistry. It should be noted that the links between outpourings and current volcanic activity are consistent with motions of the lithospheric plates.

WHITE and MCKENZIE (1989) have noted the association of flood basalts with 
Table 1.

\begin{tabular}{lllc}
\hline \multicolumn{1}{c}{ Hotspot } & \multicolumn{1}{c}{ Link } & \multicolumn{1}{c}{ Flood basalt } & Age (Myr) \\
\hline Yellowstone & Snake River Plain & Columbia River & $15 \pm 2$ \\
Afar & (contiguous) & Ethiopian & $35 \pm 2$ \\
Iceland & Iceland-Faeroe Ridge & Brito-Arctic & $57-64$ \\
Reunion & Chagos-Laccadive Is. & Deccan & $66 \pm 2$ \\
Kerguelen & Ninety-East Ridge & Rajmahal & $110 \pm 5$ \\
Tristan da Cunha & Rio-Grande Plateau & Parana & $130 \pm 5$ \\
Tristan da Cunha & Walvis Ridge & Entendeka & $135 \pm 5$ \\
Crozet & Mozambique Plateau & Karoo & $190 \pm 5$ \\
Great Meteor & New England Seamounts? & E. North Am. & $200 \pm 5$ \\
Jan Mayan & Lomonosov Ridge? & Siberian & $249 \pm 4$ \\
Hawaii & Hawaiian-Emperor & Wrangellia (?) & \\
Galapagos & Cocos Ridge & Jamaica Plateau & \\
MacDonald & Austral-Gilbert-Marshall & Shatsky Plateau & \\
Easter & Nazca \& Sala y Gomez Ridges & (subducted?) & \\
Easter & Taumoto-Line Islands & Hess Plateau & \\
Cobb Seamount & Gulf of Alaska Seamounts & (subducted?) & \\
\hline
\end{tabular}

episodes of continental rifting, and argued that the two are causally related; the rising diapir stresses the lithosphere, triggering continental breakup and the subsequent thinning and pressure-release melting producing voluminous lavas.

The association of flood basalts with hotspots and mantle plumes took on added interest when RAMPINO and STOTHERS (1988) argued that over the last 250 myr, continental flood basalts have occurred every $30 \mathrm{myr}$ and, moreover, that there is a one-to-one correspondence between these basalts and mass extinction events. They attributed this correlation to a common cause by extraterrestrial impact, even though the vast majority of geophysicists would argue that flood basalts and volcanic island chains are the result of internal processes.

This purported correlation is quite weak because the timing of the onset of most flood basalts is known only very poorly. An exception is the Deccan eruption which has been timed very close to the Cretaceous/Tertiary extinction event 66 myr ago (COURTILlOT et al., 1988). It is possible that this statistical correlation will fade as better data become available. Also, the correlation raises some difficult questions. For example, why does the correlation involve only continental events? Surely flood basalt events, if produced externally, should occur fairly randomly over the surface. (In the model of WHITE and MCKENZIE (1989) flood-basalt events occur preferentially in continental settings.) Why would the effect on life differ dramatically depending whether the event occurred on a continent or ocean? Further, how can the correlation be found to hold if only a fraction of the events (i.e., the continental events) are included? Nevertheless, the implications of such a correlation, if valid, are far-reaching and profound, implying that the course of evolution on Earth is ultimately governed by the process that causes flood basalts.

The claim that flood basalts can be caused by impacts has been analyzed by LOPER and MCCARTNEY (1990). They conclude that no viable model has yet been proposed to link impacts with flood-basalt volcanism. That is, the impact of an extraterrestrial body appears to be incapable of initiating hotspot volcanic activity, unless of course, the 
impact occurs on a pre-existing hotspot. This mechanism has been proposed by RAMPINO (1989), who argues that showers of comets occurring every 30 myr initiate flood basalts by triggering the eruption of a hotspot which has no associated surface volcanism. This mechanism, too, raises a number of questions. First, why would a random process involving several impactors in a group result in only one event per shower? Also, why would a hotspot magma need to be triggered by an external event? Volcanoes commonly erupt without an external trigger.

This work has been supported in part by the National Science Foundation under Grant \#EAR-8805349 and is contribution \#308 of the Geophysical Fluid Dynamics Institute.

\section{APPENDIX}

The purpose of this appendix is estimation of the mass averaged pressure $p_{\mathrm{m}}$, within the core:

$$
p_{\mathrm{m}}=\frac{1}{M_{\mathrm{c}}} \int_{0}^{M_{\mathrm{c}}} p \mathrm{~d} M=\frac{4 \pi}{M_{\mathrm{c}}} \int_{0}^{r_{\mathrm{c}}} p \rho r^{2} \mathrm{~d} r
$$

The data in Table II of PREM (DZIEWONSKI and ANDERSON, 1981) may be parameterized by

$$
\rho=\left[1-0.154\left(r / r_{\mathrm{i}}\right)^{2}\right] 1.309 \times 10^{4} \mathrm{~kg} / \mathrm{m}^{3}
$$

for $0<r<r_{\mathrm{i}}$ and

$$
\rho=\left[1-0.0941 \phi-0.0733 \phi^{2}-0.0185 \phi^{3}\right] 1.2166 \times 10^{4} \mathrm{~kg} / \mathrm{m}^{3}
$$

for $r_{\mathrm{i}}<r<r_{\mathrm{c}}$, where $\phi=\left(r-r_{\mathrm{i}}\right) /\left(r_{\mathrm{c}}-r_{\mathrm{i}}\right)$, and

$$
p=p_{0}\left[1-0.01134\left(r / r_{\mathrm{c}}\right)-0.8233\left(r / r_{\mathrm{c}}\right)^{2}+0.2074\left(r / r_{\mathrm{c}}\right)^{3}\right]
$$

for $0<r<r_{\mathrm{c}}$ where $p_{0}$ is the current central pressure. With this parameterization,

$$
M_{\mathrm{c}}=4 \pi \int_{0}^{r_{\mathrm{c}}} \rho r^{2} \mathrm{~d} r=1.88 \times 10^{24} \mathrm{~kg} .
$$

and the integral in (A.1) yields $p_{\mathrm{m}} / p_{0}=0.628$.

\section{REFERENCES}

Braginsky, S. I., Structure of the $F$ layer and reasons for convection in the earth's core, Dokl. Akad. Nauk $S S S R, 149,8-10,1963$.

BRAGINSKY, S. I. and V. P. MEYTLIS, Overheating instability in the lower mantle near the boundary with the core, Phys. Solid Earth, 23, 646-649, 1987.

Christensen, U., Thermal evolution models of the Earth, J. Geophys. Res., 90, 2995-3007, 1985.

Copley, S. M., A. F. Giamel, S. M. Johnson, and M. F. Hornbecker, The origin of freckles in unidirectionally solidified castings, Metall. Trans., 1, 2193-2204, 1970. 
Courtillot, V., G. Féraud, H. Maluski, D. Vandamme, M. G. Moreau, and J. Besse, Deccan flood basalts and the Cretaceous/ Tertiary boundary, Nature, 333, 843-846, 1988.

DAvies, G. F., Ocean bathymetry and plume convection 1. Large-scale flow and hotspots, J. Geophys. Res., 93, 10467-10480, 1988.

Doornbos, D. J., S. Spiliopoulos, and F. D. STACEY, Seismological properties of $D^{\prime \prime}$ and the structure of a thermal boundary layer, Phys. Earth Planet. Inter., 41, 225-239, 1986.

Dziewonski, A. M. and D. L. Anderson, Preliminary reference Earth model, Phys. Earth Planet. Inter., 25, 297-356, 1981.

FEARn, D. R. and D. E. LOPER, Pressure freezing of the Earth's inner core, Phys. Earth Planet. Inter., 39, 5-13, 1985.

FEARn, D. R., D. E. Loper, and P. H. RoberTs, Structure of the Earth's inner core, Nature, 292, 232-233, 1981.

GRIFFITHS, R. E., Thermals in extremely viscous fluids, including the effects of temperature-dependent viscosity, J. Fluid Mech., 166, 115-138, 1986.

Gubbins, D., G. Masters, and J. A. Jacobs, Thermal evolution of the Earth's core, Geophys. J. Roy. Astron. Soc., 59, 57-99, 1979.

Guggenheim, E. A., Thermodynamics, Wiley, New York, 1967.

Hall, H. T. and V. R. MURThY, The early chemical history of the Earth: Some critical element fractionations, Earth Planet. Sci. Lett., 11, 239-244, 1971.

Higgins, G. and G. C. KENNEDY, The adiabatic gradient and the melting point gradient in the core of the earth, J. Geophys. Res., 76, 1870-1878, 1971.

JACKSON, M. J. and H. N. POLLACK, On the sensitivity of parameterized convection to the rate of decay of internal heat sources, J. Geophys. Res., 89, 10103-10108, 1984.

JACOBS, J. A., The Earth's inner core, Nature, 172, 297, 1953.

Kennedy, G. C. and G. Higgins, The core paradox, J. Geophys. Res., 78, 900-904, 1973.

LOPER, D. E., The gravitationally powered dynamo, Geophys. J. Roy. Astron. Soc., 54, 389-404, 1978a.

LOPER, D. E., Some thermal consequences of a graviationally powered dynamo, J. Geophys. Res., 83, 5961-5970, 1978b.

LOPER, D. E., Structure of the core and lower mantle, Adv. Geophys., 26, 1-34, 1984.

LOPER, D. E., Mantle plumes, Tectonophys., 1990 (to appear).

LOPER, D. E. and K. MCCARTNEY, On impacts as a cause of geomagnetic field reversals or flood basalts, GSA Special Paper 247, in Global Catastrophes in Earth History: An Interdisciplinary Conference on Impacts, Volcanism, and Mass Mortality, edited by V. L. Sharpeton and P. D. Ward, 1990 (to appear).

LOPER, D. E. and P. H. RoberTs, On the motion of an iron-alloy core containing a slurry I. General theory, Geophys. Astrophys. Fluid Dyn., 9, 289-321, 1978.

LOPER, D. E. and P. H. RoberTS, On the motion of an iron-alloy core containing a slurry II. A simple model, Geophys. Astrophys. Fluid Dyn., 16, 83-127, 1980.

Loper, D. E. and P. H. RoBerts, A study of conditions at the inner core boundary of the Earth, Phys. Earth Planet. Inter., 24, 302-307, 1981.

LOPER, D. E. and F. D. STACEY, The dynamical and thermal structure of deep mantle plumes, Phys. Earth Planet. Inter., 33, 304-317, 1983.

Lowes, F. J., The geomagnetic dynamo-elementary energetics and thermodynamics, Geophys. Surv., 7, 91-105, 1984.

Malkus, W. V. R., Convection at the melting point: A thermal history of the Earth's core, Geophys. Fluid Dyn., 4, 267-278, 1973.

Melosh, H. J. and W. B. Tonks, Giant impacts, global magma oceans and geochemical differentiation: A view of the Earth's early thermal regime, EOS, Trans. Am. Geophys. Union, 70, 1000, 1989.

Morgan, W. J., Deep mantle convection plumes and plate motions, Amer. Assn. Petroleum Geol. Bull., 56, 203-213, 1972.

OLSON, P. and I. S. NAM, Formation of seafloor swells by mantle plumes, J. Geophys. Res., 91, 7181-7191, 1986.

Olson, P. and H. Singer, Creeping plumes, J. Fluid Mech., 158, 511-531, 1985.

Rampino, M. R., Impact cratering, decompression melting and hotspot volcanism, EOS, Trans. Am. Geophys. Union, 70, 1357, 1989.

RAmpino, M. R. and R. B. Stothers, Flood basalt volcanism during the past 250 million years, Science, 241, 663-668, 1988. 
Richards, M. A., R. A. Duncan, and V. E. Courtillot, Flood basalts and hot-spot tracks: Plume heads and tails, Science, 246, 103-107, 1989.

Schubert, G., Subsolidus convection in the mantles of terrestrial planets, Ann. Rev. Earth Planet. Sci., 7, 289-342, 1979.

Sharpe, H. N. and W. R. Peltier, Parameterized mantle convection and the Earth's thermal history, Geophys. Res. Lett., 5, 737-744, 1978.

Sleep, N. H. and R. T. LANGAn, Thermal evolution of the Earth: Some recent developments, Adv. Geophys., 23, 1-23, 1981 .

Stacey, F. D., A thermal model of the Earth, Phys. Earth Planet. Inter., 15, 341-348, 1977.

StaCey, F. D., The cooling Earth: A reappraisal, Phys. Earth Planet. Inter., 22, 89-96, 1980.

Stacey, F. D. and R. D. Irvine, Theory of melting: Thermodynamic basis of Lindemann's Law, Aust. J. Phys., 30, 631-640, 1977.

Stacey, F. D. and D. E. Loper, Thermal histories of the core and mantle, Phys. Earth Planet. Inter., 36, 99-115, 1984.

STACEY, F. D. and D. E. Loper, Thermal histories of the Earth: A corollary concerning non-linear mantle theology, Phys. Earth Planet. Inter., 53, 167-174, 1988.

Stevenson, D. J., Application of liquid state physics to the Earth's core, Phys. Earth Planet. Inter., 22, 42-52, 1980.

Stevenson, D. J., Temperature gradient, crystallinity and rigidity of the outer core, EOS, Trans. Am. Geophys. Union, 70, 1212, 1989.

Verhoogen, J., Energetics of the Earth, National Academy of Sciences, Washington, D.C., 1980.

Warren, P. H., The magma ocean concept and lunar evolution, Ann. Rev. Earth Planet. Sci., 13, 201-240, 1985.

White, R. and D. McKenzie, Magmatism at rift zones: The generation of volcanic continental margins and flood basalts, J. Geophys. Res., 94, 7685-7729, 1989.

WhiteheAd, J. A. and D. S. Luther, Dynamics of laboratory diapir and plume models, J. Geophys. Res., 80, $705-717,1975$.

Yuen, D. A. and W. R. Peltier, Mantle plumes and the thermal stability of the $D^{\prime \prime}$ layer, Geophys. Res. Lett., 7, 625-628, 1980. 